\title{
New reactivity patterns of copper(I) and other transition metal NHC complexes: application to ATRC and related reactions
}

\author{
James A. Bull ${ }^{\text {a }}$, Michael G. Hutchings ${ }^{\text {b }}$, Cristina Luján ${ }^{\text {a }}$, Peter Quayle ${ }^{\mathrm{a}, *}$ \\ a School of Chemistry, The University of Manchester, Manchester M13 9PL, UK \\ ${ }^{\mathrm{b}}$ DyStar UK Ltd, School of Chemistry, The University of Manchester, Manchester M13 9PL, UK
}

Received 19 October 2007; revised 14 December 2007; accepted 18 December 2007

Available online 23 December 2007

\begin{abstract} reactions.

(C) 2007 Elsevier Ltd. All rights reserved.

Keywords: ATRC; Kharasch; Cyclisation; Radical; Copper; Carbene; NHC; Nickel; Ruthenium; Palladium; Grubbs
\end{abstract}

Pre-formed transition metal-NHC complex is shown to be an effective catalyst for Atom Transfer Radical Cyclisation (ATRC)

The seminal discovery by Arduengo ${ }^{1}$ of stable carbenes possessing the general structure $\mathbf{1}$ has spurred numerous investigations from physical and theoretical chemists. ${ }^{2}$ More recently, the realisation that these intermediates could serve as phosphane surrogates in transition metal chemistry has been extensively explored by many groups, leading to the development of new catalysts which, in many cases, exhibit enhanced levels of stability or reactivity when compared to their phosphane counterparts. ${ }^{3}$ Recently the groups of Buchwald ${ }^{4 \mathrm{a}}$ and Nolan ${ }^{4 \mathrm{~b}}$ have shown that the readily available, stable copper(I)-NHC complex 2 serves as a useful catalyst in hydrosilylation, ${ }^{4 b, 5 a} \mathrm{C}-\mathrm{H}$ activation $^{5 \mathrm{~b}}$ and Huisgen dipolar cycloaddition ('click') reactions. ${ }^{5 \mathrm{c}}$ Homochiral variants of these complexes also prove to be efficient in facilitating enantioselective conjugate $^{5 \mathrm{~d}}$ addition and displacement reactions. ${ }^{5 \mathrm{e}}$
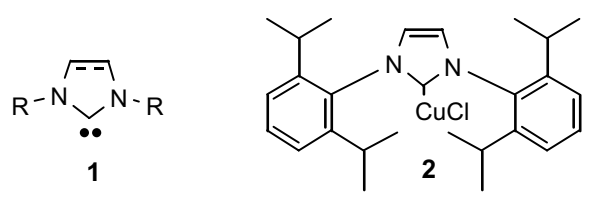

\footnotetext{
* Corresponding author. Tel.: +44 161275 4619; fax: +44 1612754598. E-mail address: peter.quayle@manchester.ac.u (P. Quayle).
}

As a continuation of our interest in the synthetic application of Atom Transfer Radical Cyclisation (ATRC) reactions $^{6}$ we recently disclosed ${ }^{7}$ that a catalyst system comprising the ligand $\mathbf{3 a}$ in conjunction with a suitable source of $\mathrm{Cu}(\mathrm{I})$, promotes a novel, regiospecific, synthetically useful, benzannulation reaction of 2-allylphenyl trichloroacetate 4 to chloronaphthalene $\mathbf{6}$, Scheme 1. We believe that this particular transformation proceeds via the intermediacy of lactone $\mathbf{5}$, the result of an initial 8-endo trig ATRC reaction. Furthermore, circumstantial evidence ${ }^{8}$

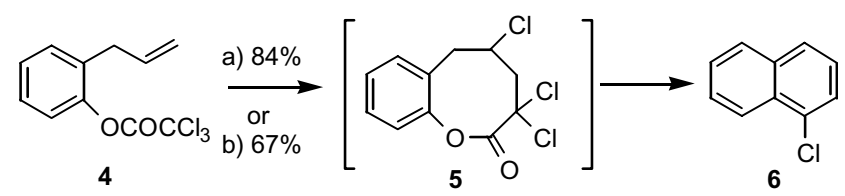<smiles></smiles>

Scheme 1. ATRC and benzannulation sequences. Reagents and conditions: (a) 3a ( $5 \mathrm{~mol} \%), \mathrm{CuCl}(5 \mathrm{~mol} \%), \mathrm{DCE}, \mu \mathrm{W}, 20{ }^{\circ} \mathrm{C}, 2 \mathrm{~h}, 84 \%$; (b) 2 $(5 \mathrm{~mol} \%)$, DCE, $\mu \mathrm{W}, 200{ }^{\circ} \mathrm{C}, 2 \mathrm{~h}, 67 \%$. DCE $=1,2$-dichloroethane. 
prompted us to consider whether the active catalytic species involved in these reactions was in fact the pincer carbene ${ }^{9}$ complex 7 rather than a pyridine- $\mathrm{Cu}(\mathrm{I}) \sigma$-complex. ${ }^{10}$ Unfortunately all attempts to validate this hypothesis have, to date, met with failure as we have been unable to prepare complex 7 using the standard methodology. ${ }^{11}$ Undeterred by these difficulties, the recent reports by Buchwald $^{4 \mathrm{a}}$ and Nolan ${ }^{4 \mathrm{~b}}$ concerning the preparation of stable NHC copper(I) complexes ${ }^{12}$ encouraged us to question whether these stable, isolable, complexes would themselves be capable of promoting ATRC reactions. ${ }^{13}$

In a preliminary experiment we were pleased to find that the thermolysis of the trichloroacetate $\mathbf{4}$ in the presence of the pre-formed carbene complex 2 under conditions of microwave irradiation ${ }^{7}\left(5 \mathrm{~mol} \%\right.$; DCE; $\mu \mathrm{W} ; 200^{\circ} \mathrm{C}, 2 \mathrm{~h}$ ) afforded 1-chloronaphthalene 6 in $67 \%$ yield after column chromatography. Inspection of the ${ }^{1} \mathrm{H}$ NMR spectrum of the crude reaction mixture revealed that the transformation had proceeded cleanly with total consumption of the starting material 4 and no apparent sign of the intermediate lactone 5. Lowering the reaction temperature to $150^{\circ} \mathrm{C}$ during irradiation resulted in a slower conversion solely to the final aromatic product $\mathbf{6}$.

Given the ability of $\mathbf{2}$ to catalyse the conversion of $\mathbf{4}$ into 6 we decided to compare its efficiency to that already established for the $[\mathrm{CuCl} \cdot \mathbf{3 a}]$ combination. Consequently a number of aryl trichloroacetates, $\mathbf{8 a}-\mathbf{k}$, were subjected to our standard benzannulation conditions (2, $5 \mathrm{~mol} \%$; DCE; $\left.\mu \mathrm{W} ; 200{ }^{\circ} \mathrm{C}, 2 \mathrm{~h}\right)$. We were pleased to find that in most cases the adoption of such a regimen cleanly afforded the respective substituted naphthalene derivatives $9 \mathbf{a}-\mathbf{k}$ in yields which are comparable to, if not better than those obtained using the $[\mathrm{CuCl} \cdot 3 \mathbf{a}]$ catalyst system (Scheme 2).

From a practical standpoint we note that the present reaction conditions appear to be cleaner than those reported previously ${ }^{7}$ and that, except for $\mathbf{8 b}$, the yields of the isolated products are higher than with the $[\mathrm{CuCl} \cdot \mathbf{3 a}]$ catalyst system. When $[\mathrm{CuCl} \cdot \mathbf{3 a}]$ is employed as catalyst an intractable granular precipitate is usually deposited during the course of the reaction; a situation which is to be compared with those reactions catalysed with $\mathbf{2}$ where reaction mixtures remain homogeneous throughout. The beneficial effects of microwave heating ${ }^{7,14,15}$ are again apparent in this transformation given that simple thermolysis of a solution of $\mathbf{4}$ and catalyst $\mathbf{2}(5 \mathrm{~mol} \%)$ in refluxing DCE initially leads to the formation of lactone $\mathbf{5}$ (over $48 \mathrm{~h}$ ), which is then slowly converted to product $\mathbf{6}$ (ca. $50 \%$ conversion after 7 days). We also conclude that in situ generation ${ }^{12}$ of 2 appears possible as addition of $\mathrm{CuCl}(5 \mathrm{~mol} \%)$ and salt $\mathbf{3 b}(5 \mathrm{~mol} \%)$ to a solution of $\mathbf{4}$ in DCE immediately prior to irradiation affords the desired naphthalene $\mathbf{6}$, albeit in a slightly reduced isolated yield of $57 \%$ (Scheme 2).

Given the ability of carbene complex 2 to promote cyclisation of $\mathbf{4}$ into $\mathbf{6}$ its efficiency in other ATRC reactions was examined. In the case of the transformation of $\mathbf{4}$ into 6 performing the reaction at lower temperatures (refluxing
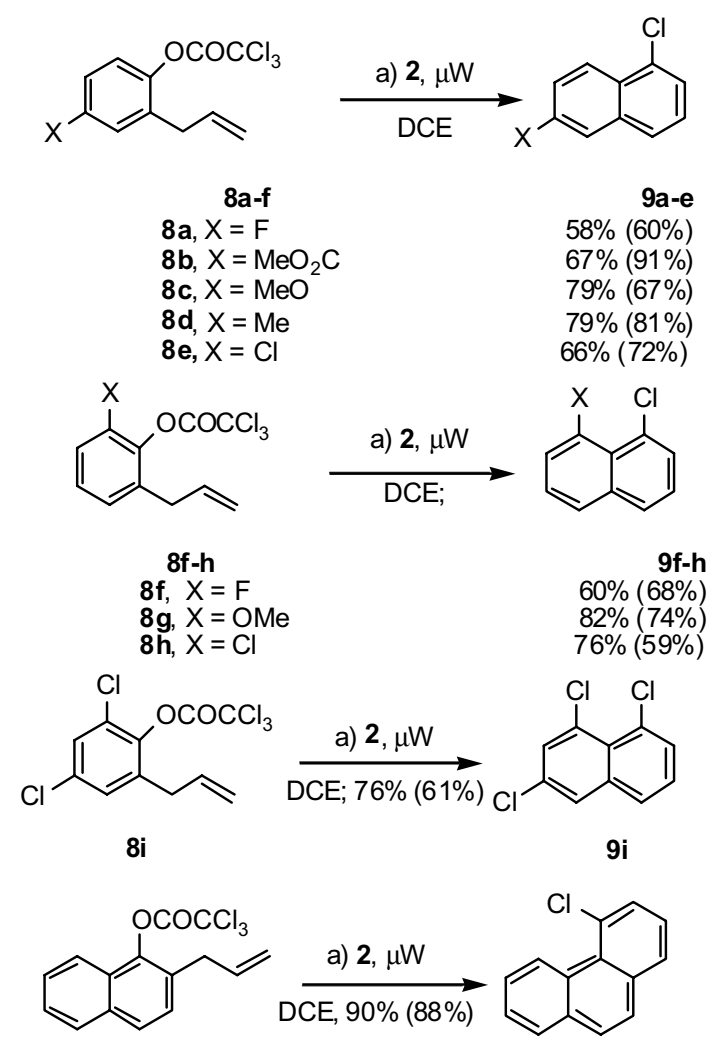

8j

9j

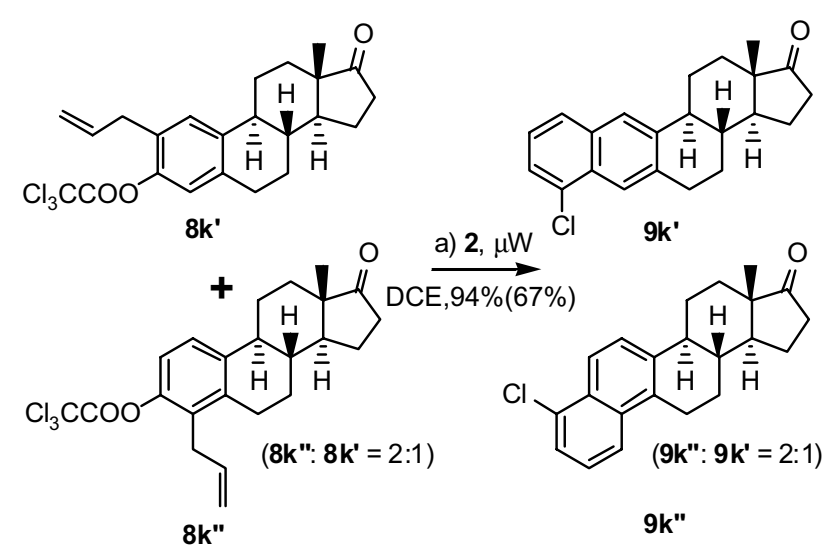

Scheme 2. Benzannulation reactions catalysed by carbene complex 2 . Reagents and conditions: (a) 2 ( $5 \mathrm{~mol} \%$ ); DCE, $\mu \mathrm{W}, 200{ }^{\circ} \mathrm{C}, 2 \mathrm{~h}$. Yields in parentheses are those obtained using $[\mathrm{CuCl} \cdot \mathbf{3 a}]$ as catalyst $(\mathrm{CuCl}, 5 \mathrm{~mol} \%$; 3a, $5 \mathrm{~mol} \%$; DCE, $\left.\mu \mathrm{W}, 200{ }^{\circ} \mathrm{C}, 2 \mathrm{~h}\right) .{ }^{7} \mathrm{DCE}=1,2$-dichloroethane.

DCE, $48 \mathrm{~h}$ ) interrupted the benzannulation reaction sequence enabling lactone 5 to be isolated in ca. $90 \%$ yield. Under these conditions the formation of the naphthalene was kept to a minimum (ca. 5\%), Scheme 3 .

Attempts to extend this regime to other substrates initially proved disappointing as the exposure of 10, 12, 14 or 16 to $2(5 \mathrm{~mol} \%)$ in either DCE or toluene at reflux afforded the desired cyclised products in only low to moderate yields (Scheme 3). Fortunately the outcome of these reactions improved dramatically when conducted in a microwave reactor ${ }^{17}\left(2,5 \mathrm{~mol} \%\right.$; DCE; $\left.\mu \mathrm{W} ; 110^{\circ} \mathrm{C}\right)$, and afforded the desired products $11,{ }^{16} \mathbf{1 3}, \mathbf{1 5}$ and 17 in good 


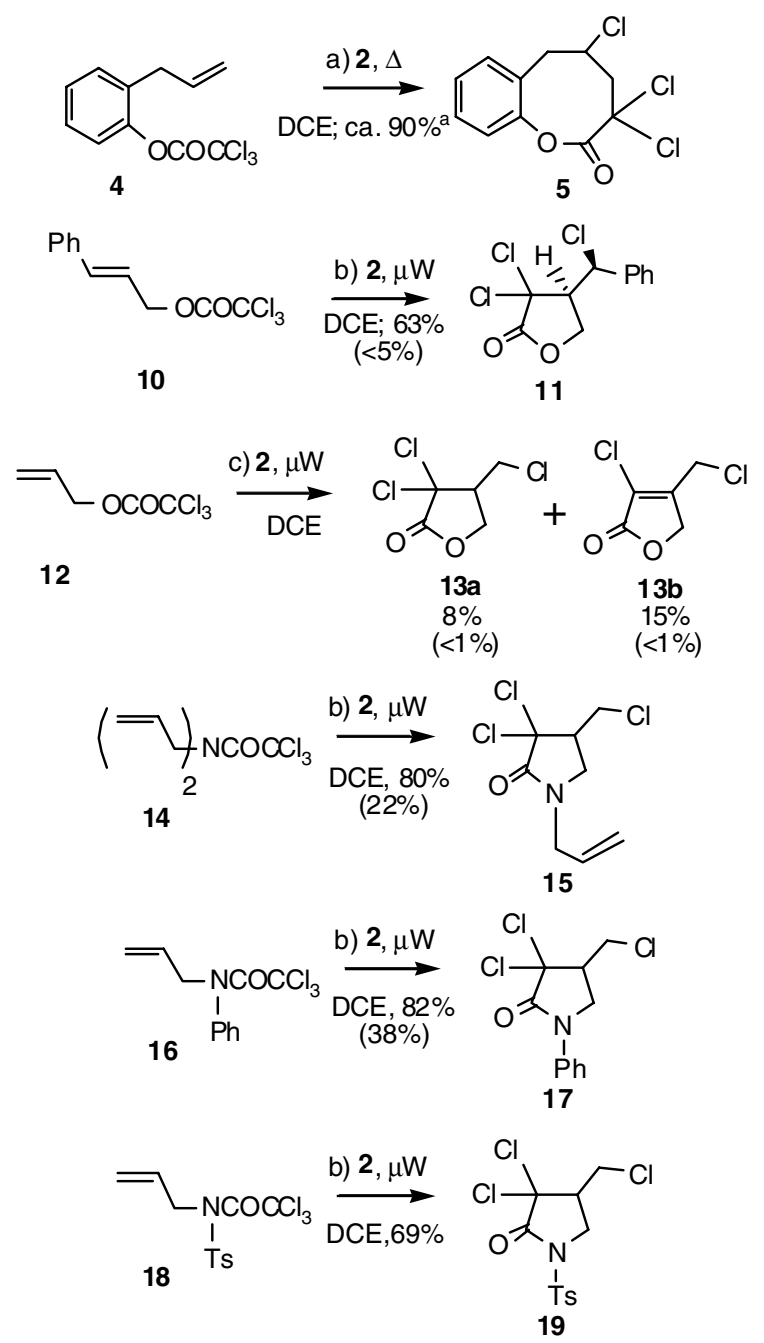

Scheme 3. ATRC reactions catalysed by carbene complex 2 . Reagents and conditions: (a) 2 (5 mol \%); DCE, $83{ }^{\circ} \mathrm{C}, 48 \mathrm{~h}$; (b) 2 (5 mol \%); DCE, $\mu \mathrm{W}$, $110^{\circ} \mathrm{C}, 3 \mathrm{~h}$; (c) $2(5 \mathrm{~mol} \%) ; 2(5 \mathrm{~mol} \%)$; DCE, $\mu \mathrm{W}, 110{ }^{\circ} \mathrm{C}, 17 \mathrm{~h}$. Yields in parentheses are those obtained by the thermolysis of the substrate in the presence of 2 in DCE at $83{ }^{\circ} \mathrm{C}$ for $3 \mathrm{~h}$. DCE $=1,2$-dichloroethane. ${ }^{a}$ Lactone $\mathbf{5}$ is unstable towards hydrolysis. This yield is based on purification by elution through Florisil $^{\circledR}$. Product contains ca. $5 \%$ of naphthalene 6.

yields after simple purification by filtration of the reaction mixture through silica, Scheme 3.

Apparently, irradiation in $\mathrm{DCE}$ at $110^{\circ} \mathrm{C}$ in the microwave reactor proves to be optimal for these particular ATRC reactions: at lower temperatures the reaction appears to be sluggish, whilst temperatures in excess of $150{ }^{\circ} \mathrm{C}$ results in much reduced isolated yields. Reduction of the catalyst loading appears to have little effect on the overall yield of these ATRC reactions as cyclisation of $\mathbf{1 6}$ in the presence of $\mathbf{2}(1 \mathrm{~mol} \%)$ afforded 17 in $63 \%$ isolated yield after a reaction time of $17 \mathrm{~h}$. Notably, examination of the ${ }^{1} \mathrm{H}$ NMR spectrum of the crude reaction mixture from the ATRC reaction of amide $\mathbf{1 4}$ clearly established that the carbene complex $\mathbf{2}$ was still present and had suffered little decomposition during the course of the reaction.
Table 1

Benzannulation reactions catalysed by pre-formed carbene complexes

\begin{tabular}{lllllllll}
\hline SM & \multicolumn{7}{c}{ Cat. } \\
\cline { 2 - 9 } & $\mathbf{2}$ & $\mathbf{2 0}$ & $\mathbf{2 1}$ & $\mathbf{2 2}^{\text {a }}$ & $\mathbf{2 3}$ & $\mathbf{2 4}$ & $\mathbf{2 5}$ & $(\mathbf{2 + 2 3})^{\text {b }}$ \\
\hline $\mathbf{4}$ & $\mathbf{6}$ & $\mathbf{6}$ & $\mathbf{6}$ & & $\mathbf{6}$ & $\mathbf{6}$ & & \\
& $(66)$ & $(69)$ & SM & ND & $(49)$ & $(23)$ & ND & ND \\
$\mathbf{8 e}$ & $\mathbf{9 e}$ & $\mathbf{9 e}$ & $\mathbf{9 e}$ & & $\mathbf{9 e}$ & $\mathbf{9 e}$ & & \\
& $(67)$ & $(52)$ & $(36)$ & ND & $(46)$ & $(11)$ & ND & ND \\
$\mathbf{8 h}$ & $\mathbf{9 h}$ & $\mathbf{9 h}$ & $\mathbf{9 h}$ & $\mathbf{9 h}$ & $\mathbf{9 h}$ & $\mathbf{9 h}$ & $\mathbf{9 h}$ & $\mathbf{9 h}$ \\
& $(76)$ & $(79)$ & SM & $(18)$ & $(55)$ & $(38)$ & $(16)$ & $(73)$ \\
\hline
\end{tabular}

Catalyst $(5 \mathrm{~mol} \%)$; DCE, $\mu \mathrm{W}, 200{ }^{\circ} \mathrm{C}, 2 \mathrm{~h}$. Figures in brackets refer to isolated yields of products.

${ }^{\text {a }}$ Reaction time of $8 \mathrm{~h}$ at $200{ }^{\circ} \mathrm{C}$.

b Catalyst comprising $5 \mathrm{~mol} \%$ of $\mathbf{2 0}$ and $5 \mathrm{~mol} \% \mathbf{2 3}$ employed in this case.

Having demonstrated that the copper(I) NHC complex 2 can catalyse ATRC reactions we have briefly screened the use of other transition metal-NHC complexes in our benzannulation reaction, Table 1 . Replacing 2 by the related copper complex $\mathbf{2 0}{ }^{19}$ has little overall effect upon the benzannulation reactions of $\mathbf{4}, \mathbf{8 e}$ and $\mathbf{8 h}$ under our standard benzannulation reaction conditions $\left(200^{\circ} \mathrm{C}\right.$; $\mu \mathrm{W}$; DCE; $2 \mathrm{~h}$ ) whereas the nickel complex $\mathbf{2 1}^{20}$ is noticeably less efficient in catalysing these reactions. The recently described PEPPSI ${ }^{\mathrm{TM}}$ palladium complex $\mathbf{2 2}^{21}$ also effects the benzannulation of $8 \mathbf{h}$ into $9 \mathbf{h}$, but reaction times have to be extended in this instance to achieve noticeable levels of conversion. Previously ${ }^{6 a}$ we had shown that the Grubbs catalyst $\mathbf{2 3}$ proves to be efficient in promoting ATRC reactions, an observation which has now been extended to our newly discovered benzannulation reaction. Hence, exposure of $4,8 \mathbf{e}$ and $\mathbf{8 h}$ to complex 23 under our usual
20<smiles></smiles>

22

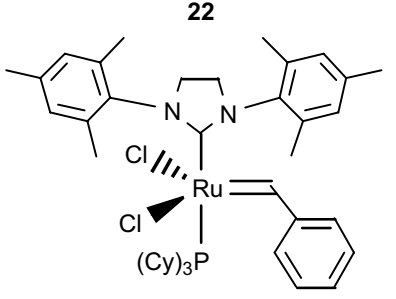

24

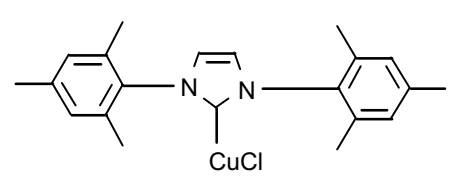<smiles>CC(C)c1cccc(C(C)C)c1N1C=CN(c2c(C(C)C)cccc2C(C)C)C1C(=O)P</smiles>

21

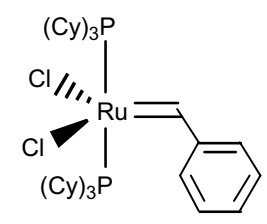

23

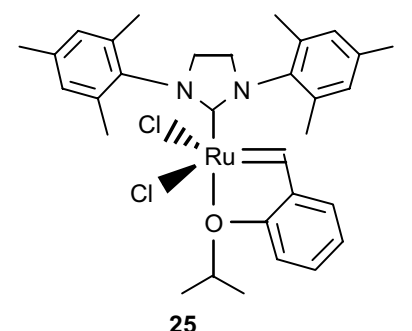


benzannulation conditions afforded $\mathbf{6}, 9 \mathrm{e}$ and $\mathbf{9 h}$ in $46-55 \%$ isolated yields. Interestingly we note that exchanging the phosphine ligand of $\mathbf{2 3}$ by a NHC ligand, as in the 2 nd generation Grubbs catalyst $\mathbf{2 4}$, apparently has a negative effect $^{22}$ upon both the rate and isolated yields of representative benzannulation reactions (Table 1). Use of catalysts possessing a hemilabile ligand, as in the case of the Hoveyda-Grubbs catalyst 25, also proves to be detrimental whilst a mixed catalyst system comprising of $\mathbf{2}$ and $\mathbf{2 3}$ has little effect on the overall efficiency of the benzannulation reaction leading to $9 \mathbf{h}$.

In conclusion we have discovered that readily available NHC-transition metal carbene complexes promote a variety of ATRC reactions. This study also demonstrates the potential benefits of microwave irradiation on metal-catalysed ATRC reactions. That several of these ATRC reactions do proceed more effectively under microwave heating may be indicative of a 'microwave effect' observation which is currently under scrutiny. The fact that the carbene complex 2 appears to be intact at the end of the reaction also suggests that recycling of the catalyst in these reactions is a distinct possibility. ${ }^{24} \mathrm{We}$ anticipate that tuning $^{25}$ (both electronic and steric) of the catalyst system will enable these reactions to proceed under milder conditions, a goal which is also the focus of current investigations. In addition we have yet to compare the reactivity of these pre-formed carbene complexes with the newly developed, and highly reactive, ruthenium ${ }^{26}$ and copper $^{27}$ catalysts under our microwave conditions.

\section{Acknowledgement}

J.A.B. and C.L. thank DyStar UK Ltd for support of this research programme.

\section{References and notes}

1. Arduengo, A. J., III. Acc. Chem. Res. 1999, 32, 913-921.

2. Alder, R. W.; Blake, M. E.; Oliva, J. M. J. Phys. Chem. (A) 1999, 103, 11200-11211.

3. Olaf, K. Chem. Soc. Rev. 2007, 36, 592-697; Dragutan, V.; Dragutan, I.; Delaude, L.; Demonceau, A. Coord. Chem. Rev. 2007, 251, 765794.

4. (a) Jurkauskas, V.; Sadighi, J. P.; Buchwald, S. L. Org. Lett. 2003, 5, 2417-2420; (b) Kaur, H.; Zinn, F. K.; Stevens, E. D.; Nolan, S. P. Organometallics 2004, 23, 1157-1160.

5. (a) Díez-González, S.; Scott, N. M.; Nolan, S. P. Organometallics 2006, 25, 2355-2358; (b) Fructos, M. R.; De Fremont, P.; Nolan, S. P.; Mar, D.-R. M.; Perez, P. J. Organometallics 2006, 25, 2237-2241; (c) Díez-González, S.; Correa, A.; Cavalo, L.; Nolan, S. P. Chem. Eur. J. 2006, 12, 7558-7564; (d) Gade, L. H.; Bellemin-Laponnaz, S. Top. Organomet. Chem. 2007, 21, 117-157; Roland, S.; Mangeney, P. Top. Organomet. Chem. 2005, 15, 191-229; Clavier, H.; Guillemin, J.-C.; Mauduit, M. Chirality 2007, 19, 471-476; (e) Gillingham, D. G.; Hoveyda, A. H. Angew. Chem., Int. Ed. 2007, 46, 3860-3864.

6. (a) Quayle, P.; Fengas, D.; Richards, S. Synlett 2003, 1797-1800; (b) Edlin, C. D.; Faulkner, J.; Fengas, D.; Knight, C. K.; Parker, J.; Preece, I.; Quayle, P.; Richards, S. N. Synlett 2005, 572-576; (c) Faulkner, J.; Edlin, C. D.; Fengas, D.; Preece, I.; Quayle, P.; Richards, S. N. Tetrahedron Lett. 2005, 46, 2381-2385; (d) Helliwell,
M.; Fengas, D.; Knight, C. K.; Parker, J.; Quayle, P.; Raftery, J.; Richards, S. N. Tetrahedron Lett. 2005, 46, 7129-7134; (e) Edlin, C. D.; Faulkner, J.; Quayle, P. Tetrahedron Lett. 2006, 47, 1145-1151; (f) Edlin, C. D.; Faulkner, J.; Helliwell, M.; Knight, C. K.; Parker, J.; Quayle, P.; Raftery, J. Tetrahedron 2006, 62, 3004-3015; (g) Edlin, C. D.; Faulkner, J.; Fengas, D.; Helliwell, M.; Knight, C. K.; House, D.; Parker, J.; Preece, I.; Quayle, P.; Raftery, J.; Richards, S. N. J. Organomet. Chem. 2006, 691, 5375-5382.

7. Bull, J. A.; Hutchings, M. G.; Quayle, P. Angew. Chem., Int. Ed. 2007, 46, 1869-1872.

8. Conducting these reactions with, for example, bipy-based ligand systems rapidly generates green-coloured solutions, presumably due to the generation of $\mathrm{Cu}$ (II) complexes. In the case of (pro)ligand 3a this is not the case thereby leading us to speculate as to the nature of the catalytic species in this particular case.

9. Michon, C.; Ellern, A.; Angelici, R. J. Inorg. Chim. Acta 2006, 359, 4549-4556; For a review on 'tethered' carbenes see: Liddle, S. T.; Edworthy, I. S.; Arnold, P. L. Chem. Soc. Rev. 2007, 36, 1732-1744.

10. For the X-ray structure of an analogous zinc complex see: Wan, X.-J.; Xu, F.-B.; Li, Q.-S.; Song, H.-B.; Zhang, Z.-Z. Acta Crystrallogr., Sect. E 2005, 61, m2174-m2175.

11. See Herrmann, W. A.; Weskamp, T.; Böhm, V. P. W. $A d v$. Organomet. Chem. 2001, 48, 1-69 and references cited therein.

12. Complex $\mathbf{2}$ is now commercially available from Strem Chemicals.

13. For the use of Ru carbene complexes in (i) ATRC reactions see Ref. 6a; (ii) ATRP/Kharasch reactions see: Delaude, L.; Demonceau, A.; Noels, A. F. Top. Organomet. Chem. 2004, 11, 155-171 and references cited therein; We are aware of a single report concerning the use of copper carbene complexes as catalysts in ATRP recations, see: Bantu, B.; Wang, D.; Wurst, K.; Buchmeiser, M. R. Tetrahedron 2005, 61, 12145-12152.

14. For use of microwave activation of Kharasch reactions see: (a) Adámek, F.; Hájek, M. Tetrahedron Lett. 1992, 33, 2039-2042; ultrasound irradiation: (b) Shvekhgeimer, M.-G. A.; Kobrakov, K. I.; Gafarov, D. M. Dokl. Akad. Nauk. 2001, 377, 210-211.

15. Whilst there is a growing body of applications to ATRP chemistry see: (a) Zhang, H.; Schubert, U. S. Macromol. Rapid Commun. 2004, 25, 1225-1230; (b) Leenen, M.; Wiesbrock, F.; Hoogenboom, R.; Schubert, U. S. e-Polymers, 2005, No. 071 (http://www.e-polymers.org); (c) Wiesbrock, F.; Hoogenboom, R.; Schubert, U. S. Macromol. Rapid Commun. 2004, 25, 1739-1764; (d) Cheng, Z.; Zhu, X.; Zhou, N.; Zhu, J.; Zhang, Z. Radiat. Phys. Chem. 2005, 72, 695701; (e) Delfosse, S.; Wei, H.; Demonceau, A.; Noels, A. F. Polym. Prepr. 2005, 46, 295-296; (f) Delfosse, S.; Borguet, Y.; Delaude, L.; Demonceau, A. Macromol. Rapid Commun. 2007, 28, 492-503; utilisation of this technique in ATRC/group transfer cyclisation reactions is under-represented (see: (g) Wetter, C.; Studer, A. Chem. Commun. 2004, 174-175; (h) Ericsson, C.; Engman, L. J. Org. Chem. 2004, 69, 5143-5146. for pertinent examples).

16. Isolated as a single diastereoisomer which is identical to that reported in Ref. 6a.

17. Representative experimental procedures: Benzannulation reactions: A solution of ester $\mathbf{8 h}(500 \mathrm{mg}, 1.6 \mathrm{mmol})$ and the catalyst $\mathbf{2}(38.8 \mathrm{mg}$, $0.08 \mathrm{mmol})$ in dry DCE $(6 \mathrm{~mL})$ was heated in a microwave reactor ${ }^{18}$ at $200{ }^{\circ} \mathrm{C}$ under nitrogen for $2 \mathrm{~h}$. Upon cooling to ambient temperature the solvent was removed in vacuo and the crude product purified by flash column chromatography (eluent petrol) to afford 1,8dichloronaphthalene 9h. Yield $240.0 \mathrm{mg}$ (76\%). IR $v_{\max }$ (film): 1597, $1553,1501,1359,1324,1195,1153,970,887 \mathrm{~cm}^{-1}$; ${ }^{1} \mathrm{H}$ NMR $\left(500 \mathrm{MHz}, \mathrm{CDCl}_{3}\right) \delta 8.20(2 \mathrm{H}, \mathrm{dd}, J=8,1 \mathrm{~Hz}), 7.83(2 \mathrm{H}, \mathrm{dd}$, $J=7.5,1 \mathrm{~Hz}), 7.37(2 \mathrm{H}, \mathrm{dd}, J=8,7.5 \mathrm{~Hz}) \mathrm{ppm} ;{ }^{13} \mathrm{C} \mathrm{NMR}$ (125.75 MHz, $\left.\mathrm{CDCl}_{3}\right): 137.2,130.9,130.4,128.5,127.5,126.2 \mathrm{ppm}$; $m / z$ (EI/CI): $195 / 197 / 199,161 / 163,125$. Accurate mass: $\mathrm{C}_{10} \mathrm{H}_{6} \mathrm{O}^{35} \mathrm{Cl}_{2}$ $\left(\mathrm{M}^{+}\right)$requires 195.9841; found 195.9844. ATRC reactions: A solution of $N$-allyl-2,2,2-trichloro- $N$-phenylacetamide, $16(500 \mathrm{mg}, 1.9 \mathrm{mmol})$ and catalyst $2(45.5 \mathrm{mg}, 0.09 \mathrm{mmol})$ in DCE $(6 \mathrm{~mL})$ was heated in a microwave reactor ${ }^{18}$ at $110^{\circ} \mathrm{C}$ under nitrogen for $3 \mathrm{~h}$. Upon cooling to ambient temperature the solvent was removed in vacuo and the 
crude product purified by flash column chromatography (eluent: petrol-AcOEt 9:1 v/v) to afford lactam 19. Yield $409.3 \mathrm{mg}(82 \%)$, mp $138-139^{\circ} \mathrm{C}$. IR $v_{\max }$ (film): 3061, 1709, 1495, 1410, 1305, 817, $762 \mathrm{~cm}^{-1} ;{ }^{1} \mathrm{H}$ NMR $\left(500 \mathrm{MHz}, \mathrm{CDCl}_{3}\right) \delta 7.55(2 \mathrm{H}, \mathrm{br} \mathrm{d}, J=8 \mathrm{~Hz}$, ArH), $7.34(2 \mathrm{H}$, app. tr., $J=8 \mathrm{~Hz}), 7.18(1 \mathrm{H}$, app. tr., $J=8 \mathrm{~Hz})$, $3.97-4.03(2 \mathrm{H}, \mathrm{m}), 3.75(1 \mathrm{H}$, app. tr., $J=10 \mathrm{~Hz}), 3.64(1 \mathrm{H}, \mathrm{dd}$, $J=10,9 \mathrm{~Hz}), 3.13-3.20(1 \mathrm{H}, \mathrm{m}) \mathrm{ppm} ;{ }^{13} \mathrm{C}$ NMR $(125.75 \mathrm{MHz}$, $\left.\mathrm{CDCl}_{3}\right): 164.4,137.9,129.6,126.2,120.2,84.1,50.9,49.1,41.0 \mathrm{ppm}$, $m / z$ (EI/CI): $277 / 278 / 279 / 280 / 281 / 282$. Accurate mass: $\mathrm{C}_{11} \mathrm{H}_{11} \mathrm{O}^{35}$ $\mathrm{Cl}_{3} \mathrm{~N}\left([\mathrm{M}+1]^{+}\right)$requires 277.9901; found 277.9909.

18. A Biotage Initiator ${ }^{\mathrm{TM}}$ microwave reactor (maximum power output of $300 \mathrm{~W}$; operating frequency $2450 \mathrm{MHz}$ ) was used throughout.

19. Lebel, H.; Davi, M.; Diezz-Gonzalez, S.; Nolan, S. P. J. Org. Chem. 2007, 72, 144-149 and reference cited therein.

20. Matsubara, K.; Ueno, K.; Shibata, Y. Organometallics 2006, 25, $3422-3427$.

21. Organ, M. G.; Avola, S.; Dubovyk, I.; Hadei, N.; Kantchev, E. A. B.; O'Brien, C. J.; Valente, C. Chem. Eur. J. 2006, 12, 47494755.

22. Demonceau has previously noted a similar effect in ATRP reactions: Simal, F.; Delfosse, S.; Demonceau, A.; Noels, A. F.; Denk, K.; Kohl, F. J.; Weskamp, T.; Herrmann, W. A. Chem. Eur. J. 2002, 8, 30473052. We thank a referee for this observation.
23. Demonceau et al. ${ }^{15 f}$ have observed a 'microwave effect' during Rucatalysed ATRP reactions when conducted in a microwave reactor. For a leading reference to this contentious issue see: Dressen, M. H. C. L.; van de Kruijis, B. H. P.; Meuldijk, J.; Vekemans, J. A. J. M.; Hulshof, L. A. Org. Process Res. Dev. 2007, 11, 865-869; Demonceau et al. has also recently reported the use of monomode microwave irradiation in intermolecular ATRA reactions: Borguet, Y.; Richel, A.; Delfosse, S.; Leclerc, A.; Delaude, L.; Demonceau, A. Tetrahedron Lett. 2007, 48, 6334-6338.

24. Afonso, C. A. M.; Branco, L. C.; Candeias, N. R.; Gois, P. M. P.; Lourenço, N. M. T.; Mateus, N. N. M.; Rosa, J. N. Chem. Commun. 2007, 2669-2679.

25. See Gómez-Bujedo, S.; Alcarazo, M.; Pichon, C.; Álvarez, E.; Fernández, R.; Lassaletta, J. M. Chem. Commun. 2007, 11801182 for the transmission of substituent effects in $\mathrm{Ru}$ carbene complexes.

26. See Thommes, K.; Icli, B.; Scopeliti, R.; Severin, K. Chem. Eur. J. 2007, 13, 6899-6907 and references cited therein.

27. For example, Muñoz-Molina, J. M.; Caballero, A.; Díaz-Requejo, M. M.; Trofimenko, S.; Belderraín, T. R.; Pérez, P. J. Inorg. Chem. 2007, 46, 7725-7730; Tang, H.; Arulsamy, N.; Radosz, M.; Shen, Y.; Tsarevsky, N. V.; Braunecker, W. A.; Tang, W.; Matyjaszewski, K. J. Am. Chem. Soc. 2006, 128, 16277-16285. 